\title{
Word of Mouth : Pengaruh Terhadap Keputusan Pembelian Konsumen (Studi Kasus pada CV. Arto Jaya Abadi di Bandar Lampung)
}

\author{
Andi Malawenta ${ }^{1}$, Ahiruddin $^{1 *}$, Sodirin $^{1}$ \\ ${ }^{1}$ Universitas Sang Bumi Ruwa Jurai \\ ${ }^{*}$ Correspondence : ahiruddin@fe.saburai.ac.id
}

\begin{abstract}
Abstrak.
Tujuan penelitian untuk mengetahui pengaruh Word of Mouth (WOM) terhadap pembelian konsumen CV. Arto Jaya Abadi. Metode penelitian yang digunakan dalam penelitian menggunakan metode penelitian deskritif kuntitatif. Teknik pengumpulan data yang digunakan adalah observasi dan kuesioner. Jumlah sampel sebanyak 35 konsumen tetap CV. Arto Jaya Abadi di Bandar Lampung. Hasil pengujian hipotesis pengaruh Word of

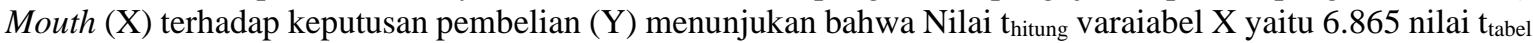
yaitu 1.724. Karena $\mathrm{t}_{\text {hitung }}>\mathrm{t}_{\text {tabel }}$, maka Ha diterima artinya Word of Mouth berpengaruh positif terhadap keputusan pembelian CV. Arto Jaya Abadi di Bandar lampung. Kontribusi ( $R$ Square) sebesar 0.588 artinya sebesar $58.8 \%$ variasi perubahan variabel keputusan pembelian mampu dijelaskan oleh variabel Word of Mouth. Sedangkan sisanya (41.2\%) dijelaskan oleh variabel lain diluar dari variabel penelitian ini.
\end{abstract}

Kata kunci: Commanditaire Vennootschap, Keputusan Pembelian, Word of Mouth

\begin{abstract}
.
The purpose of the study was to determine the effect of Word of Mouth (WOM) on consumer purchases of CV. Arto Jaya Abadi. The research method used in this research is descriptive quantitative research method. Data collection techniques used are observation and questionnaires. The number of samples as many as 35 permanent consumers CV. Arto Jaya Abadi in Bandar Lampung. The results of testing the hypothesis of the influence of Word of Mouth $(X)$ on purchasing decisions $(Y)$ show that the tcount value of the $X$ variable is 6.865, the ttable value is 1.724. Because tcount > ttable, then Ha is accepted, meaning that Word of Mouth has a positive effect on CV purchasing decisions. Arto Jaya Abadi in Bandar Lampung. The contribution ( $R$ Square) of 0.588 means that $58.8 \%$ of the variation in changes in the purchasing decision variables can be explained by the Word of Mouth variable. While the rest (41.2\%) is explained by other variables outside of this research variable.
\end{abstract}

Keywords: Commanditaire Vennootschap, Purchase Decision, Word of Mouth

\section{PENDAHULUAN}

Dampak pandemi Covid-19 terhadap berbagai sektor ekonomi tentunya berbeda kedalamannya, namun tidak bisa dipungkiri bahwa sebagian besar berdampak negative (Muhyiddin \& Nugroho, 2020). Berdasarkan Riset Nielsen yang bertajuk "Race Against the Virus, Indonesian Consumer Response towards COVID-19" mengungkapkan bahwa sebanyak 50\% masyarakat Indonesia mulai mengurangi aktivitas di luar rumah (Siahaan, 2020), hal ini sangat mempengaruhi pendapatan pedagang yang pada akhirnya akan mempengaruhi keuntungan yang diterima (Sinaga \& Purba, 2020). Padahal, Ekonomi merupakan faktor yang terpenting dalam kehidupan manusia. Kebutuhan ekonomi erat kaitannya dalam kehidupan sehari-sehari (Yamali \& Putri, 2020). Di Indonesia hampir semua sektor bisnis mengalami kerugian akibat dampak pandemic covid-19 ini (Avriyanti, 2021). Dalam hal ini perusahaan harus bekerja keras untuk menciptakan kebijakan yang efektif dan kreatif (Hendrawan et al., 2019) 
dalam memasarkan produk atau jasa mereka ke konsumen(Fadly \& Sutama, 2020), salah satunya dengan memberikan pelayanan yang terbaik. Terpuruknya Ekonomi Indonesia membuat nilai tukar Rupiah terhadap dollar menurun, hal tersebut bisa kita lihat dari grafik naik turunnya nilai mata uang Dolar dibawah ini:

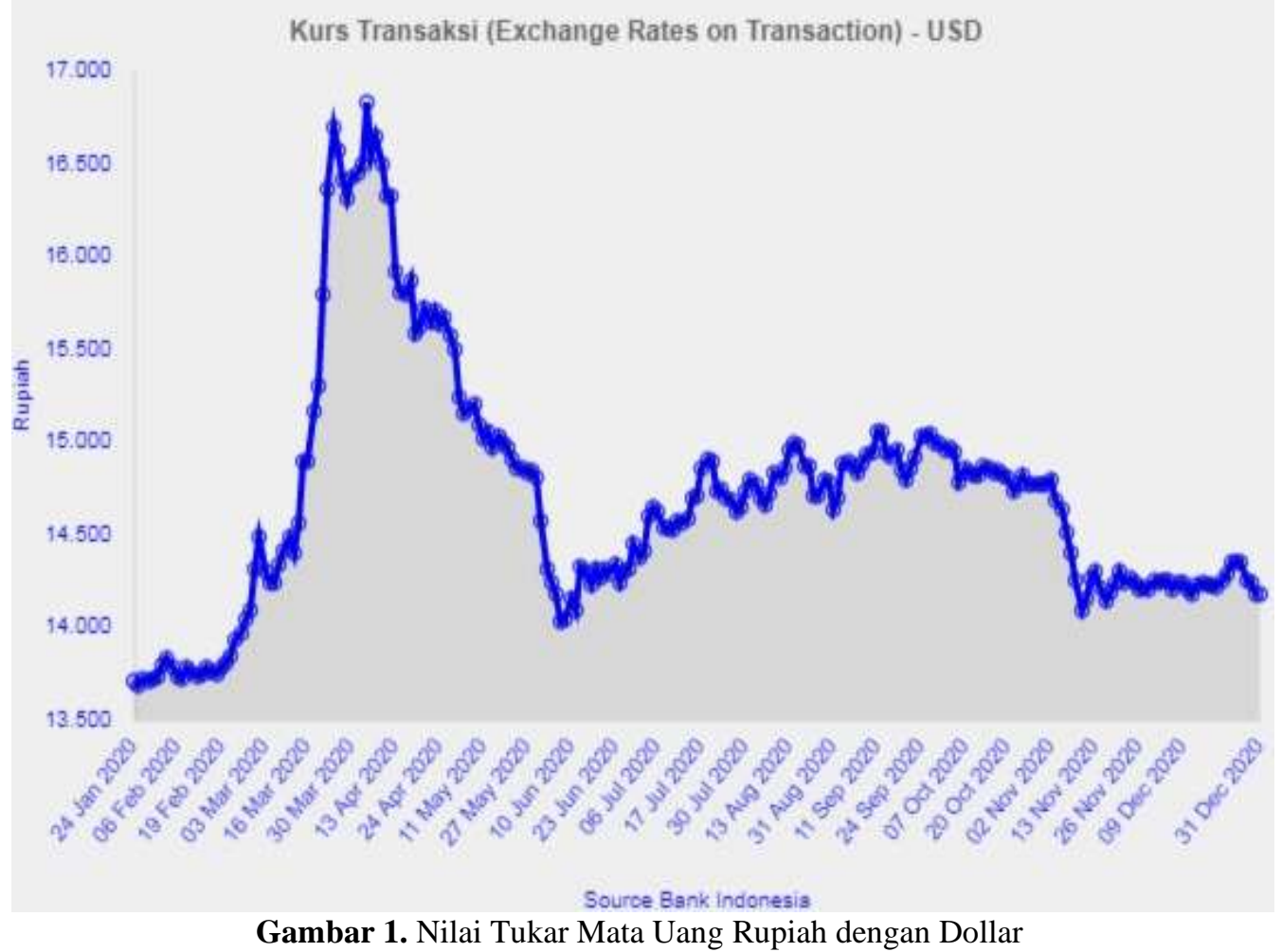

Dari tabel diatas bisa dilihat nilai tukar mata uang bulan Januari hingga awal Maret 2020 mengalami kenaikan yang tidak signifikan, namun pada April hingga Desember 2020 nilai mata uang dolar menggalami fluktuatif karena kinerja perekonomian melemah tersebut.

Selain itu, semenjak pandemi ini merebak di Indonesia mengakibatkan diberlakukannya Pembatasan Sosial Berskala Besar (PSBB) (Khairu Nissa et al., 2020), dengan adanya PSBB diperluas ke seluruh Indonesia maka otomatis dampak kerugian perekonomian membesar, Pemutusan Hubungan Kerja (PHK) yang dilakukan oleh beberapa perusahaan kepada para pekerja dengan alasan force majeure atau mengalami kerugian (Juaningsih, 2020) dan juga sebagian masyarakat mengalami penurunan daya beli karena menurunannya penghasilan dan PHK, di sisi lain terjadi panic buying (Khusnul, 2021).
Salah satu usaha yang terdampak karena covid-19 ini adalah CV. Arto Jaya Abadi. CV. Arto Jaya Abadi yang didirikan sejak 19 Januari 2016 yang bergerak di bidang General Supplier yang beralamat di Jl.Akasia Blok A3 No.16 Kelurahan Beringin Raya Kecamatan Kemiling Bandar Lampung mengalami penurunan pembelian dan pendapatan. Padahal CV. Arto Jaya Abadi sudah melakukan berbagai promosi antara lain meneyebarkan brosur, iklan dikoran, maupun pamplet. Berikut data promosi yang dilakukan oleh Cv. Arto Jaya Abdi :

Tabel 1. Data Promosi CV. Arto Jaya Abadi

\begin{tabular}{cccc}
\hline Tahun & Brosur & Koran & Pamplet \\
\hline 2018 & 2 & 4 & 4 \\
2019 & 2 & 4 & 4 \\
2020 & 2 & 4 & 4 \\
\hline
\end{tabular}

Tabel di atas menjelaskan tentang data promosi yang ada di CV. Arto Jaya Abadi dan bentuk promosi yang sedang dilakukan 
saat ini adalah Word of Mouth (WOM). Dimana cara ini lebih efektif dilaksanakan karena targetnya adalah menciptakan kesan baik yang berasal dari satu orang ke orang lain. Namun CV. Arto Jaya Abadi tetap mengalami penurunan penjualan yang terlihat dari data 3 tahun terakhir berikut:

Tabel 2. Data Penjualan CV. Arto Jaya Abadi

\begin{tabular}{cccc}
\hline Tahun & Total Penjualan/Tahun & Target Penjualan/Tahun & $\begin{array}{c}\text { Presentase Penjualan } \\
(\mathbf{\%})\end{array}$ \\
\hline 2018 & Rp. 65.781.976,412 & Rp. 60.000 .000 & $0,91 \%$ \\
2019 & Rp. 69.987.750,320 & Rp. 65.000 .000 & $0,93 \%$ \\
2020 & Rp. 55.987.850,255 & Rp. 67.000 .000 & $1,16 \%$ \\
\hline
\end{tabular}

Berdasarkan data penjualan di atas maka, semenjak tahun 2020 tepatnya Ketika pandemic mulai merebak CV. Arto Jaya Abadi mengalami penurunan padahal di tahun 2018 dan 2019 penjualan mengalami kenaikan. Selain itu, target penjualan pada tahun 2020 pun tidak terpenuhi. Padahal jika dilihat 22 tahun sebelumnya, total penjualan dapat melampaui target yang sudah ditentukan di CV. Arto Jaya Abadi.

Kondisi penjualan yang berfluktuasi tersebut tidak terlepas oleh yang namanya persaingan (Oktaviandi, 2020) dan permasalahan pemasaran. Dengan banyaknya persaingan maka CV. Arto Jaya Abadi dituntut untuk membuat strategi yang optimal dalam penjualan barang dan jasa sehingga konsumen dapat meningkat. Maka berikut adalah daftar dari konsumen $\mathrm{CV}$. Arto Jaya Abadi :

Tabel 3. Daftar Konsumen CV.Arto Jaya Abadi

\begin{tabular}{cl}
\hline No. & \multicolumn{1}{c}{ Daftar Nama Konsumen } \\
\hline 1 & PT. Wijaya Karya Beton TBK \\
2 & PT. Bukit Asam TBK \\
3 & CV. Kopkar Bara \\
4 & PT. Oto Multiarha \\
5 & PT. Waskita Karya \\
6 & CV. Bintang Kencana Tehnik \\
7 & PT. Sugiono Sejahtera Abadi \\
8 & PT. Warna Mardhika \\
9 & PT. Surya Cipta Engineering \\
10 & CV. Prawita Utama Konsultan \\
11 & PT. Wungu Sejahtera Wijaya \\
12 & PT. Tiga Jaya Kencana \\
13 & PT. Berkah Lancar Lestari \\
14 & PT. Genta Buana Nusantara \\
15 & PT. Citra Primadona Perkasa \\
16 & PT. Lampung Indah Permai \\
17 & CV. Putra Jaya \\
18 & CV. Guruh Karya Mandiri
\end{tabular}

\begin{tabular}{cl}
\hline No. & \multicolumn{1}{c}{ Daftar Nama Konsumen } \\
\hline 19 & CV. Sumber Berkah Wijaya \\
20 & CV. Traco Perdana \\
21 & CV. Kurnia Adigana \\
22 & CV. Putra Komputer \\
23 & PT. Asmi Hidayat \\
24 & CV. Titian Kencana \\
25 & CV. Mandiri Global Security \\
26 & PT. Karya Perdana Baru \\
27 & PT. Mitra Agung \\
28 & PT. Setiawan Sedjati \\
29 & PT. Mitra Solusi Interteknologi \\
30 & PT. Dms Konsultan \\
31 & CV. Anugrah Semesta Lampung \\
32 & PT. Shahgosan Makmur Sentosa \\
33 & PT. Securindo Parkatama \\
34 & PT. Anugrah Kreasi \\
35 & CitiHub Hotel \\
\hline
\end{tabular}

Melihat jumlah konsumen, CV. Arto Jaya Abadi cukup dipercaya oleh perusahaan. Namun Perusahaan General Supplier di Bandar Lampung pun cukup banyak sehingga persaingan bisnis semakin kompetitif. Maka berikut adalah daftar nama kompotitor CV.Arto Jaya Abdai :

Tabel 4. Daftar Kopetitor CV. Arto Jaya Abadi

\begin{tabular}{|c|l|}
\hline No. & \multicolumn{1}{|c|}{ Daftar Nama Kompotitor } \\
\hline 1 & PT. Penamart Supplier \\
\hline 2 & PT. Stationry Srore \\
\hline 3 & CV. Andalas Kencana \\
\hline 4 & PT. Multi Jaya Mandiri \\
\hline 5 & PT. Jasa Prima Surya \\
\hline
\end{tabular}

Melihat jumlah beberapa kompetitor usaha yang bergerak di bidang supplier yang mempunyai produk dan jasa yang sama dengan CV. Arto Jaya Abadi. Kompetitor sering kali dianggap suatu tantangan atau resiko yang harus ditaklukkan agar usaha yang dijalankan menjadi berhasil dan 
mendapatkan keuntungan (Farhaby, 2019). Untuk dapat bertahan dalam dunia bisnis yang kondisi persaingannya terus meningkat, maka suatu perusahaan harus dituntut dapat menguasai pasar dengan menggunakan produk yang telah dihasilkannya (Rasul, 2017). Tiap perusahaan hendaknya memiliki strategi pemasaran yang terbaik untuk menciptakan kepuasan pembeli untuk mendukung keputusan pembelian (Naninsih \& Hardiyono, 2019). Salah satu strategi pemasaran yang digunakan dan menjadi strategi promosi personal yang sederhana yaitu strategi "WOM" (Word of Mouth) atau strategi "mulut ke mulut" (Fadillah, 2015).

Menurut WOMMA (Word of Mouth Marketing Association) menjelaskan bahwa Word of Mouth (WOM) yaitu: usaha pemasaran yang memicu konsumen untuk membicarakan, mempromosikan, merekomendasikan, dan menjual produk/merek kita kepada pelanggan lainya (Muammar Rinaldi \& Christine, 2020; Mujahid et al., 2018; Rasyid et al., 2018; Wiwik Putri Wahyu Ningsi, 2021). Menurut Sernovitz, Word of Mouth sebagai suatu tindakan dimana perusahaan memberikan alasan atau sebuak topik yang menarik agar orang-orang membicarakan produk yang dijualnya serta memudahkan pembicaraan itu terjadi (Munda, 2019). Word of Mouth bisa dilakukan secara sengaja maupun tidak sengaja, perlu untuk menerapkan beberapa elemen dasar agar penyebarnya informasi melalui Word of Mouth dapat berjalan dengan baik. terdapat lima dimensi atau elemen dasar Word of Mouth yang dikenal dengan 5T, yaitu: talkers (pembicara), topics (topik), tools (alat), talking part (partisipasi) dan tracking (pengawasan) (Karini \& Nurani, 2019).

Talkers (Pembicaraan) adalah ini adalah kumpulan target dimana mereka yang akan membicarakan suatu merek biasa disebut juga influencer. Talkers ini bisa saja melalui dari teman, tetangga, keluarga, rekan kerja, serta kerabat terdekat lainya. Selalu ada orang yang antusias untuk bicara. Mereka ini yang paling semangat menceritakan pengalamannya. Topics (Topik), ini berkaitan dengan apa yang diberikan oleh talkers. Topik ini berhubungan dengan apa yang ditawarkan oleh suatu merek. Seperti tawaran spesial, diskon, produk baru, atau pelayanan yang memuaskan. Topik yang baik adalah topik yang simpel, mudah dibawa, dan natural. Seluruh Word of Mouth memang bermula dari topik yang sangat bagus untuk dibicarakan.

Tools (Alat), ini merupakan alat peneyebaran dari topic dan talker. Topik yang telah ada juga membutuhkan suatu alat yang mebantu agar topik atau pesanan dapat berjalan. Alat ini membantu orang agar topik atau pesan dapat berjalan. Alat ini membuat orang mudah membicarakan atau menularkan produk atau jasa prusahaan kepada orang lain. Talking part (partisipasi), suatu pembicaraan akan hilang jika hanya ada satu orang yang berbicara mengenai suatu produk. Maka perlu adanya orang lain yang ikut serta adanya percakapan agar Word of Mouth dapat terus berjalan. Dan yang terakhir, Tracking (Pengawasan), adalah suatu tindakan perusahaan untuk mengawasi serta memantau respon konsumen. Hal ini dilakukan agar perusahaan dapat mempelajari masukan positif atau negatif konsumen, sehingga perusahaan dapat belajar dari masukan tersebut untuk kemajuan yang lebih baik (Amran et al., 2020).

Dengan elemen - elemen yang telah dijelaskan diatas, dapat dikatakan bahwa Word of Mouth merupakan strategi pemasaran yang dapat dilakukan oleh siapa saja dan cukup efektif. Dari hasil penjelasan menegenai jenis promosi yang dialakukan $\mathrm{CV}$. Arto Jaya Abadi serta beberapa dugaan yang dijelaskan diatas sebelumnya. Maka tujuan penelitian ini adalah Tujuan penelitian untuk mengetahui pengaruh Word of Mouth (WOM) terhadap pembelian konsumen CV. Arto Jaya Abadi.

\section{METODE PENELITIAN}


Metode penelitian yang digunakan dalam penelitian menggunakan metode penelitian deskritif kuntitatif. Objek penelitian adalah CV. Arto Jaya Abadi yang beralamatkan di jalan Akasia Blok A3 No. 12 Kelurahan Beringin Raya, Kecamatan Kemilling, Kota Bandar Lampung. Penelitian dilakukan pada bulan April sampai dengan Juni 2021.

Variabel bebas (X) adalah Word of Mouth dan Variabel terikat (Y) adalah Keputusan Pembelian. Metode pengumpulan penelitian ini adalah observasi dan angket (Questionary). Sampel yang diambil adalah konsumen CV. Arto Jaya Abadi sebanyak 35 konsumen. Analisis data menggunakan analisis regresi linear sederhana yaitu Uji-t.

\section{HASIL DAN PEMBAHASAN}

Setelah data dikumpulkan, dilanjutkan ke tahap analisis data. Penghitungan statistik regresi linier sederhana pengaruh Word of Mouth terhadap Keputusan Pembelian perlu membuat sebuah rumusan hipotesis penelitian sebagai berikut:

Ho: Tidak ada pengaruh yang signifikan Word of Mouth terhadap Keputusan Pembelian.

Ha: Terdapat pengaruh yang signifikan Word of Mouth terhadap Keputusan Pembelian.

Apabila nilai $t_{\text {hitung }}>t_{\text {tabel, }}$ maka Ho ditolak dan Ha diterima. Sebaliknya, apabila nilai $t_{\text {hitung }}<\mathrm{t}_{\text {tabel, }}$ maka Ho diterima dan $\mathrm{Ha}$ ditolak. Hasil dari perhitungan statistik regresi linier sederhana pengaruh word of mouth terhadap penjualan adalah sebagai berikut :

Tabel 5. Hasil Uji Regresi Linear Sederhana

Coefficients $^{\mathrm{a}}$

\begin{tabular}{|c|c|c|c|c|c|}
\hline \multirow[t]{2}{*}{ Model } & \multicolumn{2}{|c|}{$\begin{array}{c}\text { Unstandardized } \\
\text { Coefficients }\end{array}$} & \multirow{2}{*}{$\begin{array}{c}\begin{array}{c}\text { Standardized } \\
\text { Coefficients }\end{array} \\
\text { Beta } \\
\end{array}$} & \multirow[t]{2}{*}{$\mathbf{t}$} & \multirow[t]{2}{*}{ Sig. } \\
\hline & B & Std. Error & & & \\
\hline 1 (Constant) & 10.270 & 4.471 & & 2.297 & .028 \\
\hline Strategi.Promosi & .774 & .113 & .767 & 6.865 & .000 \\
\hline
\end{tabular}

Dari table di atas, didapat Hasil pengujian statistik dengan SPSS pada variabel Word of Mouth (X) diperoleh nilai $\mathrm{t}_{\text {hitung }}=6.865>\mathrm{t}_{\text {tabel }}=1.724$ dengan Nilai Sig. $=0.000<0.005$, jadi Ho ditolak. Ini berarti variabel Word of Mouth (X) berpengaruh signifikan terhadap variabel dependen yaitu keputusan pembelian (Y). Selain itu, Hasil koefisien arah regresi antara Word of Mouth (X) terhadap keputusan pembelian (Y) didapat nilai constant (a) sebesar 10.270 sedangkan nilai trust (b/ koefisien regresi) sebesar 0.774 , sehingga persamaan regresinya dapat ditulis:

$$
\begin{aligned}
& \mathrm{Y}=\mathrm{a}+\mathrm{bX} \\
& \mathrm{Y}=10.270+0.774 \mathrm{X}
\end{aligned}
$$

Persamaan tersebut dapat diartikan bahwa setiap penambahan $1 \%$ nilai trust, maka nilai partisipasi bertambah sebesar 0.774. Koefisien regresi tersebut bernilai positif, sehingga dapat dikatakan bahwa arah pengaruh variabel Word of Mouth (X) terhadap keputusan pembelian (Y) adalah postif.

Seberapa jauh variabel Word of Mouth menjelaskan variabel keputusan pembelian dapat ditentukan berdasarkan nilai koefisien determinasi $\left(\mathrm{R}^{2}\right)$ di bawah ini.

Tabel 6. Uji Koefisien Determinasi 
Model Summary

\begin{tabular}{lrrrr}
\hline Model & R & R Square & $\begin{array}{c}\text { Adjusted R } \\
\text { Square }\end{array}$ & $\begin{array}{c}\text { Std. Error of the } \\
\text { Estimate }\end{array}$ \\
\hline 1 & $.767^{\mathrm{a}}$ & 588 & \multicolumn{5}{c}{.576} & 3.387 \\
\hline a. Predictors: (Constant), Promosi & & & &
\end{tabular}

Dari tabel di atas diketahui bahwa kontribusi (Rsquare) sebesar 0.588 artinya sebesar $58.8 \%$ variasi perubahan variabel penjualan keputusan pembelian mampu dijelaskan oleh variabel strategi promosi sedangkan sisanya sebesar $41,2 \%$ lagi dijelaskan oleh variabel lain di luar dari variabel penelitian ini.

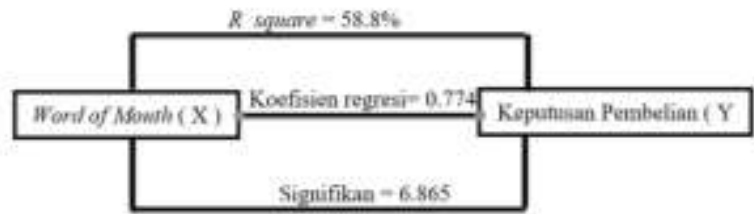

Gambar 2. Regresi Sederhana Antar Variabel

Hasil penelitian ini sama dengan hasil penelitian terdahulu yang dilakukan (Andari \& Napu, 2016) yaitu terdapat pengaruh yang signifikan antara word of mouth terhadap keputusan pembelian. Selain itu terdapat juga studi-studi yang melakukan penelitian dengan hasil yang sama antara lain riset yang dilakukan oleh (Paulus et al., 2015) dengan hasil Word of mouth berpengaruh secara simultan terhadap keputusan berkunjung wisatawan.

\section{KESIMPULAN}

Berdasarkan hasil penelitian diperoleh kesimpulan bahwa berdasarkan hasil pengujian hipotesis mengenai pengaruh Word of Mouth (X) terhadap Keputusan Pembelian (Y) menunjukkan bahwa Nilai $t_{\text {hitung }}$ yaitu 6.865 dan nilai $t_{\text {tabel }}$ yaitu 1.724. karena $t_{\text {hitung }}>\mathrm{t}_{\text {tabel }}$ maka Ha diterima, artinya Word of Mouth berpengaruh positif terhadap Keputusan Pembelian di CV. Arto Jaya Abadi di Bandar lampung. Kontribusi ( $R$ Square) sebesar 0.588 yang berate sebesar $58.8 \%$ variasi perubahan variabel keputusan pembelian mampu dijelaskan oleh variabel Word of Mouth. Sedangkan sisanya $41.2 \%$ lagi dijelaskan oleh variabel lain di luar dari variabel penelitian ini.

\section{DAFTAR PUSTAKA}

Amran, A., Widjaja, Y. R., \& Kamelia, E. (2020). the Role of Social Media Marketing and Word of Mouth in Building Brand Awareness At Brownies Vannisa. Procuratio: Jurnal Ilmiah Manajemen, 8(2), 237-243.

Andari, R., \& Napu, D. M. (2016). Pengaruh word of mouth terhadap keputusan pembelian tiket maskapai penerbangan domestik di davina tour and travel gorontalo. THE Journal: Tourism and Hospitality Essentials Journal, 6(1), 1013-1022.

http://www.bssaonline.org/content/95/6 /2373\%5Cnhttp://www.bssaonline.org/ content/95/6/2373.short\%0Ahttp://ww w.bssaonline.org/cgi/doi/10.1785/0120 110286\%0Ahttp://gji.oxfordjournals.or g/cgi/doi/10.1093/gji/ggv142\%0Ahttp:/ /link.springer.com/10.1007/s00024013-0646

Avriyanti, S. (2021). Strategi Bertahan Bisnis Di Tengah Pandemi Covid-19 Dengan Memanfaatkan Bisnis Digital (Studi Pada UKM yang Terdaftar pada DInas Koperasi, Usaha Kecil, dan Menengah Kabupaten Tabalong). Jurnal PubBis, 5(1), 60-74. https://doi.org/10.35722/pubbis.v5i1.38 0

Fadillah, D. (2015). Model Komunikasi "WOM" Sebagai Strategi Pemasaran Efektif. Humanika, 15(1), 66-74. https://doi.org/10.21831/hum.v15i1.76 42

Fadly, H. D., \& Sutama, S. (2020). Membangun Pemasaran Online Dan 
Digital Branding Ditengah Pandemi Covid-19. Jurnal Ecoment Global: Kajian Bisnis Dan Manajemen, 5(2), 213-222.

http://ejournal.uigm.ac.id/index.php/E G/article/view/1042

Farhaby, A. M. (2019). Analisis Usaha Perikanan Tangkap Kapal Bagan di Pulau Celagen Kecamatan Kepulauan Pongok Kabupaten Bangka Selatan. Aquatic Science, 1(1), 33-37. https://www.journal.ubb.ac.id/index.ph p/aquaticscience/article/view/874

Hendrawan, A., Sucahyowati, H., Cahyandi, K., Indriyani, \& Rayendra, A. (2019). Pengaruh Marketing Digital Terhadap Kinerja Penjualan Produk UMKM Asti Gauri di Kecamatan Bantasari Cilacap. Jurnal Administrasi Dan Kesekretarisan, 4(1), 50-61. http://www.jurnal.stikstarakanita.ac.id/index.php/JAK/article/ view/189/136

Juaningsih, I. N. (2020). Analisis Kebijakan PHK Bagi Para Pekerja Pada Masa Pandemi Covid-19 di Indonesia. "adalah : Buletin Hukum Dan Keadilan, 4(1), 189-196. http://journal.uinjkt.ac.id/index.php/ada lah/article/view/15764

Karini, R. S. R. A., \& Nurani. (2019). Word of Mouth Terhadap Keputusan Berkunjung di tahura Ir. H. Djuanda. Jurnal Riset Bisnis Dan Manajemen, 12(1), 43-49.

Khairu Nissa, N., Nugraha, Y., Finola, C. F., Ernesto, A., Kanggrawan, J. I., \& Suherman, A. L. (2020). Evaluasi Berbasis Data: Kebijakan Pembatasan Mobilitas Publik dalam Mitigasi Persebaran COVID-19 di Jakarta. Jurnal Sistem Cerdas, 3(2), 84-94. https://doi.org/10.37396/jsc.v3i2.77

Khusnul, F. (2021). Penurunan daya beli vs panic buying di tengah pandemi covid19. bagaimana tinjauan syariahnya? Jurnal Syarikah: Jurnal Ekonomi Islam, $7(1)$, $18-25$ https://ojs.unida.ac.id/JSEI/article/view
14151

Muammar Rinaldi, \& Christine. (2020). Pengaruh Kualitas Produk, Harga, Dan Word of Mouth Terhadap Customer Satisfiction Pada Produk Wallpaper (Ud. Elegance Interior). Jurnal Manajemen Bisnis Eka Prasetya: Penelitian Ilmu Manajemen, 6(1), 4151.

https://doi.org/10.47663/jmbep.v6i1.39

Muhyiddin, \& Nugroho, H. (2020). Edisi Khusus tentang Covid-19, New Normal, dan Perencanaan Pembangunan. Jurnal Perencanaan Pembangunan: The Indonesian Journal of Development Planning, 4(2), 4-7. https://doi.org/10.36574/jpp.v4i2.120

Mujahid, A., Isharyani, M. E., \& Widada, D. (2018). Analisis Strategi Pemasaran Mengunakan Metode Quantitative Strategic Planning Matrik (QSPM) Studi Kasus: Borneo Project. Jurnal Rekayasa Sistem Industri, 7(2), 111. https://doi.org/10.26593/jrsi.v7i2.2995. 111-118

Munda, N. C. P. (2019). Pengaruh Word Of Mouth Terhadap Keputusan Pembelian di Van Hengel Katering Bandung. Sekolah Tinggi Pariwisata Bandung.

Naninsih, N., \& Hardiyono, H. (2019). Pengaruh Strategi Pemasaran Terhadap Kepuasan Dan Keputusan Pembelian Produk Usaha Kecil Menengah (UKM) 310 Di Makassar. Jurnal Aplikasi Manajemen \& Kewirausahaan MASSARO, 1(1), 47-61. https://doi.org/10.37476/massaro.v1i1. 644

Oktaviandi, R. (2020). Analisis Strategi Pemasaran Ikan Pada Kelompok Tani Sugoi's Kabupaten Sukabumi. Syntax Idea, 2(10), 827-836. http://www.akrabjuara.com/index.php/ akrabjuara/article/view/919

Paulus, J. J. ., Bessie, J. L. ., \& Kasim, A. (2015). Pengaruh Word of Mouth (WOM) Terhadap Keputusan Berkunjung Wisatawan Di Kampung Adat Boti Kabupaten TTS. Journal of 
Management: Small and Medium Enterprises (SMEs), 1(1), 37-61.

Rasul, H. A. (2017). STRATEGI PEMASARAN DALAM MENINGKATKAN VOLUME PENJUALAN PRODUK. Jurnal BISNIS \& KEWIRAUSAHAAN, 6(1), 69-79.

Rasyid, R. A., Moniharapon, S., \& Trang, I. (2018). Pengaruh Strategi Promosi Melalui Social Media, Kualitas Layanan Dan Word of Mouth Terhadap Keputusan Pembelian Sepeda Motor Suzuki Pada Pt. Sinar Galesong Mandiri Malalayang Manado. Jurnal EMBA: Jurnal Riset Ekonomi, Manajemen, Bisnis Dan Akuntansi, 6(4), 3933-3942. https://doi.org/10.35794/emba.v6i4.219 18

Siahaan, M. (2020). Dampak Pandemi Covid-19 Terhadap Dunia Pendidikan. Jurnal Kajian Ilmiah, 1(1), 1-3. https://doi.org/10.31599/jki.v1i1.265

Sinaga, R., \& Purba, M. R. (2020). Pengaruh Pandemi Virus Corona (Covid-19) Terhadap Pendapatan Pedagang Sayur Dan Buah Di Pasar Tradisional "Pajak Pagi Pasar V" Padang Bulan. Regionomic, 2(02), 37-48.

Wiwik Putri Wahyu Ningsi, S. E. (2021). Pengaruh Promosi Di Media Sosial Dan Word Of Mouth Terhadap Keputusan Pembelian Skincare MS GLOW. JURNAL MANAJEMEN MODAL INSANI DAN BISNIS (JMMIB), 2(1), 50-57. www. jurnal.imsi.or.id

Yamali, F. R., \& Putri, R. N. (2020). Dampak Covid-19 Terhadap Ekonomi Indonesia. Ekonomis: Journal of Economics and Business, 4(2), 384388.

https://doi.org/10.33087/ekonomis.v4i2 .179 